\title{
Quasi-static axial and lateral crushing of radial corrugated composite tubes
}

\begin{abstract}
This paper presents the effect of corrugation geometry on the crushing behavior, energy absorption, failure mechanism, and failure mode of woven roving glass fibre/epoxy laminated composite tube. Experimental investigations were carried out on three geometrical different types of composite tubes subjected to axial and lateral compressive loadings. On the addition to a radial corrugated composite tube, cylindrical composite tube, and corrugated surrounded by cylindrical tube were fabricated and tested under the same condition in order to know the effect of corrugation geometry. The results showed that the loading carrying capability is significantly influenced by corrugation geometry in axial crushing. However, no affect of corrugation geometry was observed for lateral crushing. Load-displacement curve was plotted for all conducted tests, thus clear comparison between different specimen's geometry was achieved. It is also found that radial corrugation could significantly applicable as a stable and effective energy absorber.
\end{abstract}

Keyword: Corrugated composite tubes, Energy absorption capability, Axial compression crushing 